Estudios Constitucionales, Año 16, No 2, 2018, pp. 339-368

ISSN 07180195

Centro de Estudios Constitucionales de Chile Universidad de Talca

“¿Debería incorporarse en el Sistema Interamericano de Derechos Humanos

la noción de margen de apreciación nacional?"

David Lovatón Palacios

\title{
¿DEBERÍA INCORPORARSE EN EL SISTEMA INTERAMERICANO DE DERECHOS HUMANOS LA NOCIÓN DE MARGEN DE APRECIACIÓN NACIONAL?*
}

\author{
SHOULD THE NOTION OF DOMESTIC MARGIN OF APPRECIATION BE \\ INCLUDED IN THE INTER-AMERICAN Human RightS SySTEM?
}

\author{
David Lovatón Palacios ${ }^{* *}$ \\ Universidad Católica del Perú \\ davidlovaton@gmail.com
}

RESUMEN: El margen de apreciación nacional, de origen europeo, es un concepto del que se ha comenzado a sugerir su aplicación en el Sistema Interamericano de Derechos Humanos (SIDH). El presente artículo argumenta, en cambio, que esta noción no es necesaria ni conveniente, al poder recurrirse a los principios de subsidiariedad y de proporcionalidad en los dos supuestos en que el margen de apreciación nacional podría ser aplicable: en la determinación de la debida protección de los derechos fundamentales por parte de un Estado en cada caso concreto y en la implementación de lo dispuesto por la Comisión o la Corte Interamericana de Derechos Humanos en sede nacional. Para ello, previamente desarrolla el contexto de las relaciones de articulación dialógica entre el SIDH y los tribunales nacionales; contexto en el cual se inserta el debate sobre el margen de apreciación nacional en el ámbito interamericano.

ABSTRACT: The domestic margin of appreciation, of European origin, is a concept from which a certain part of the Latin American doctrine has begun to suggest its application in the Inter-American Human Rights System (SIDH). The present article argues, by contrast, that this notion is neither necessary nor convenient, since it is possible to use the principles of subsidiarity and proportionality in the two cases in which the domestic margin of appreciation could be applicable: in the determination of the appropriate protection of fundamental rights by a State in each specific case and in the implementation of the provisions of the Inter-American Commission or Court of Human Rights at domestic level. For this purpose, it previously develops the context of dialogical articulation relations between the SIDH and the domestic courts; context in which the debate on the domestic margin of appreciation in the Inter-American sphere is inserted.

\footnotetext{
* Trabajo recibido el 22 de diciembre de 2017 y aprobado el 1 de agosto de 2018.

El presente artículo es una actualización de parte del libro "La gestación del Estado constitucional interamericano" y de una ponencia expuesta en las Segundas Jornadas Latinoamericanas sobre Derechos Fundamentales. LOVATÓN (2017a, 2017b).

** Abogado, Doctor en Derecho y Magíster en Derecho Constitucional. Profesor principal de la Facultad de Derecho de la Pontificia Universidad Católica del Perú (PUCP). Director del Centro de investigación, Capacitación y Asesoría Jurídica (CICAJ) del Departamento Académico de Derecho de la PUCP. Consultor de la Fundación para el debido proceso (DPLF, por sus siglas en inglés).
} 
PALABRAS CLAVE: Sistema Interamericano de Derechos Humanos; Margen de apreciación nacional; Principio de proporcionalidad; Principio de subsidiariedad; Tribunales nacionales.

KEY WORDS: Inter-American Human Rights System; Margin of appreciation; Principle of proportionality; Principle of subsidiarity; Domestic courts.

\section{INTRODUCCIÓN}

El Sistema Interamericano de Derechos Humanos (SIDH), conformado por la Comisión Interamericana de Derechos Humanos (CIDH) y la Corte Interamericana de Derechos Humanos (Corte IDH), cada día dialoga y se articula más con los tribunales nacionales de América Latina, en una relación de cooperación o de tensión que en los últimos años ha enriquecido en forma recíproca tanto al sistema interamericano como a los sistemas de justicia nacionales, en especial, a la justicia constitucional ${ }^{1}$. En los últimos 50 años, el SIDH se ha erigido como una valiosa frontera - muchas veces la última frontera- de defensa de los derechos humanos en las Américas, tanto frente a regímenes autoritarios como a crisis humanitarias o situaciones estructurales de vulneración de derechos fundamentales en democracia ${ }^{2}$.

En ese marco institucional de -lo que planteamos denominar- creciente articulación dialógica entre los ámbitos interamericano y nacional, cabe preguntarse si la noción de "margen de apreciación nacional" -surgida en el seno del Sistema europeo de derechos humanos-, debería ser acogida -o no- en dicho marco institucional interamericano -y no europeo- de articulación dialógica.

\section{ARTiCUlación dialógica ENTRE SISTEMa INTERAMERICANO Y TRIBUNALES NACIONALES}

Mariela Morales Antoniazzi sostiene que: "El proceso de apertura del Estado en América Latina se distingue por dos cambios de paradigma, como son el

\footnotetext{
1 Este proceso de recíproca influencia se ha caracterizado como de internacionalización del derecho constitucional y, a su vez, de constitucionalización del derecho internacional de los derechos humanos.

2 Sobre el particular, Jorge Carpizo, cuando fue perito ante la Corte Interamericana en el Caso López Mendoza vs. Venezuela, sostuvo que "[1]a Convención Americana y su interpretación de última instancia, realizada por la Corte Interamericana de Derechos humanos (Corte IDH), está creando un ius commune latinoamericano de derechos humanos, que implica que cualquier habitante de la región goza de un mínimo de derechos que la Constitución de cada país puede ampliar, pero nunca restringir, en virtud de las obligaciones internacionales que cada Estado contrajo al ratificar la propia Convención Americana y aceptar la jurisdicción obligatoria de la Corte IDH”. Citado por BogDandy (2013), p. 43.
} 
surgimiento del paradigma del pluralismo normativo y la internacionalización entendida como humanización. El primero tiene implicaciones directas en la transformación del concepto clásico de soberanía, la superación de la concepción de un Estado cerrado y su consiguiente pérdida del carácter omnicomprensivo en el ámbito del derecho constitucional"3.

En cuanto a la humanización del derecho internacional, coincidimos cuando se afirma que "el Derecho internacional ha dejado desde hace tiempo de configurarse (únicamente) como Derecho de los Estados para adoptar un planteamiento, en cambio (también) de Derecho para los individuos"4.

De esta manera, la tradicional noción de soberanía nacional ha cedido terreno a un pluralismo normativo en el que la consagración y tutela de los derechos fundamentales ahora transcienden las fronteras nacionales.

En esta articulación dialógica entre el sistema interamericano y los tribunales nacionales, constituyen engranajes claves i) los propios Estados nacionales, que no desaparecen sino que se reposicionan en este nuevo contexto de pluralismo normativo que ahora marca la relación entre el derecho internacional y el derecho nacional, ii) la creciente articulación dialógica, que comprende al diálogo judicial pero no se agota en él y iii) la interrogante de si en el marco institucional interamericano, debería acogerse - o no- la noción de margen de apreciación nacional surgida en el seno del Sistema europeo de derechos humanos.

\subsection{Relevancia de Estados nacionales en contexto de pluralismo normativo}

En cuanto a la relevancia de los Estados nacionales, el desplazamiento del paradigma de la soberanía nacional por el paradigma del pluralismo normativo, no significa en absoluto la desaparición o irrelevancia de los Estados nacionales, los mismos que conservan una importancia vital en la vigencia de los derechos fundamentales. En tal sentido, hay que distinguir entre soberanía nacional y Estado nacional.

Los Estados nacionales siguen siendo relevantes en este nuevo contexto, entre otras razones, por la naturaleza subsidiaria de los sistemas internacionales de protección de derechos, lo que supone, por un lado, su intervención sólo en

3 Morales (2014), p. 266.

4 Vergottini (2011), p. 89. 
defecto de protección nacional y, por otro lado, la realización interna de estándares internacionales por parte de tribunales nacionales, a través, por ejemplo, pero no sólo, de técnicas como el control de convencionalidad5.

Al respecto, Armin von Bogdandy sostiene que "el nuevo universalismo que sirve de pilar del concepto de un derecho común latinoamericano no es un universalismo que señale que el Estado nación debe superarse. El Estado nación es un elemento central en esta nueva visión del nuevo derecho público, pero involucrado en un sistema internacional. El Estado y la soberanía no desaparecen, sino que se han transformado en conceptos ajustados a los nuevos tiempos"6.

Esta relevancia de los Estados nacionales para los sistemas internacionales de protección de derechos es más intensa aún en el sistema interamericano de derechos humanos, pues el mismo ha evolucionado en una atmósfera institucional que no es de integración regional -como es el caso de la Unión Europea-, sino en el de la Organización de Estados Americanos (la OEA), espacio de cooperación hemisférica, caracterizado en los últimos años por su precariedad política y financiera.

De esta manera, cada vez que los Estados nacionales de América Latina calibran sus ordenamientos jurídicos a los estándares de derechos humanos desarrollados por la Comisión y la Corte interamericanas, no sólo contribuyen a legitimar estos órganos sino que también desincentivan que sus ciudadanos recurran al sistema interamericano en búsqueda de protección de sus derechos fundamentales, pues los mismos serán debidamente tutelados en sede nacional.

Por otro lado, este Estado nacional contemporáneo se inserta en un contexto de derecho internacional marcado por el pluralismo normativo. Ello nos lleva a referirnos brevemente a la naturaleza monista ${ }^{7}$, dualista ${ }^{8}$ o pluralista de la relación entre el derecho internacional y el derecho nacional. Armin von Bogdandy sostiene al respecto que "[e]l debate doctrinal quizás más clásico en el derecho

\footnotetext{
5 El expresidente de la Corte Interamericana, Sergio García Ramírez, llega a afirma que "[...] la gran batalla por los derechos humanos se ganará en el ámbito interno, del que es coadyuvante o complemente, no sustituto, el internacional". BAZÁN (2012), p. 19.

6 Bogdandy (2013), p. 53.

7 "La teoría monista [...] considera que el derecho internacional y el derecho nacional son elementos interdependientes de un sistema cerrado. Con base en esto, la mayor parte de los representantes de la doctrina monista del derecho internacional le atribuyen prevalencia al derecho internacional [...]”. HeRDEGEN (2005), p. 167.

8 "La doctrina dualista se remite para tal efecto al hecho de que los dos ordenamientos (derecho internacional y derecho nacional) tienen fuentes y mecanismos de aplicación propios [...]” Herdegen (2005), p. 167.
} 
internacional público es el referente a su relación con los ordenamientos jurídicos internos y gira en torno a los conceptos antagónicos de monismo y dualismo" 9 . Nosotros coincidimos con este autor cuando sostiene que:

[L]os conceptos de monismo y dualismo ya no son útiles como conceptos básicos [...] Como teorías, el monismo y el dualismo son hoy en día insatisfactorias: sus argumentos son bastante herméticos [...] Tal vez pueden ser útiles para indicar una disposición política más o menos abierta hacia el derecho internacional [...] La concepción general de la relación entre las normas internacionales y las del derecho interno debería asentarse en otra base conceptual ${ }^{10}$.

Alfredo Vítolo coincide con este balance de la situación actual de la relación entre el derecho internacional y el derecho nacional, al sostener que la creciente integración entre ambos derechos invita a superar la dicotomía entre monismo y dualismo:

Poco a poco, el derecho internacional de los derechos humanos avanza hacia un reconocimiento verdaderamente universal de los derechos individuales, por encima de los ordenamientos jurídicos domésticos, modificando y limitando el tradicional concepto de soberanía estatal. De allí surge la necesidad que este "nuevo" derecho se integre al derecho interno de los estados, superando la antigua dicotomía monismodualismo, que ya había sido criticada a principios del siglo pasado por autores como Kelsen o Mirkine Guetzévitch [... $]^{11}$.

De esta manera, la superación conceptual del monismo y el dualismo lleva a la noción contemporánea de pluralismo normativo entre el derecho internacional y el derecho nacional, que supone la vigencia simultánea de varios ordenamientos jurídicos, esto es, que "[e]l principal razonamiento jurídico descansa [...] en la asunción pluralista de diversos ordenamientos" 12 en el mundo globalizado de hoy en día. Bogdandy también propone que dicha relación podría ser caracterizada como de "acoplamiento entre ordenamientos jurídicos"13, expresión ante

\footnotetext{
9 Bogdandy (2012), p. 21.

10 Bogdandy (2012), pp. 22-25, énfasis nuestro. Inclusive, el autor llega a afirmar -en forma algo provocadora, ciertamente- que el monismo y el dualismo "desde una perspectiva jurídica y académica son unos zombis intelectuales de otro tiempo que deben descansar en paz o deconstruirse". BoGDANDY (2012), p. 25.

11 Vitolo (2013), p. 361.

12 Bogdandy (2012), p. 26.

13 Bogdandy (2012), p. 26.
} 
la cual, nosotros preferimos la noción de articulación dialógica, pues la primera lleva pensar en una relación más estática entre derecho internacional y derecho nacional, en tanto la segunda invita a concebir una relación más dinámica y fluida, en constante movimiento.

$\mathrm{Al}$ respecto, César Landa recurre a la noción de "armonización” para caracterizar la relación entre derecho interamericano y derecho nacional ${ }^{14}$; noción que tampoco nos convence porque lleva a pensar en una relación más armónica de la que se da en la realidad, la misma que no está exenta de tensiones y conflictos. En cambio, la expresión "articulación” es más neutra en ese sentido y permite pensar en una relación armónica y conflictiva a la vez.

De esta manera, caracterizar la relación entre los ordenamientos interamericano y nacionales como de articulación dialógica -en un contexto de pluralismo normativo-, consideramos refleja mejor la naturaleza plural y multiforme de dicha relación, que se puede materializar en un diálogo judicial, en control de convencionalidad, en enfrentamientos o tensiones -abiertas o no- entre el sistema interamericano y los tribunales nacionales, en acatamientos de decisiones interamericanas, entre otras expresiones.

\subsection{Diálogo judicial y articulación dialógica}

En cuanto al "diálogo judicial"15, en la actualidad una importante tendencia doctrinal en el derecho constitucional postula la necesidad o conveniencia de propiciar el mismo entre tribunales nacionales e internacionales, como una de las mejores formas de armonizar los diversos niveles normativos de reconocimiento de los derechos fundamentales.

Esta noción de diálogo judicial surge en Europa ${ }^{16}$, en el contexto institucional de la integración comunitaria europea y, más recientemente, ha sido incorporada a la reflexión en torno a la relación entre la Corte interamericana y las cortes

14 " $[\mathrm{N}]$ o se debe postular la derogación automática de las normas internas en caso de conflicto con sus obligaciones en el plano internacional, ni el desconocimiento de estas últimas en el orden nacional, sino su armonización fundamentándose en la mejor protección de la persona humana”. LANDA (2012), p. 439.

15 Véase López y SAiz (2015).

16 Hacen referencia a la misma autores europeos como Luis López GuerRA, Alejandro SAIz Arnaiz, Laurence Burgorgue-Larsen, Rafael Bustos o Aída Torres, en tanto que hacen los mismos autores americanos como César Landa, Pedro Grández, Marcelo Neves o George Bandeira. Hay otros autores europeos que también hacen referencia al diálogo judicial, pero en clave crítica, como es el caso de Giuseppe de Vergottini y Javier García Roca. 
nacionales. Siendo una noción sugerente, corresponde sin embargo aproximarnos críticamente a la misma para evitar la "importación" de instituciones jurídicas en el sentido que hace ya muchos años advirtiera en el Perú Luis Hurtado Pozo en su libro La ley importada ${ }^{17}$.

Sobre la noción de diálogo judicial, Javier García Roca se interroga ¿a qué llamamos "diálogo judicial" entre el Tribunal Europeo de Derecho Humanos (TEDH) y los tribunales nacionales? ${ }^{18} \mathrm{Si}$ bien responde con doce proposiciones dirigidas a caracterizar esta noción, parte de la constatación de que "[...] La idea de 'judicial dialogue' es una noción bastante imprecisa, está repleta de intuiciones y puede que no sea todavía una verdadera categoría jurídica en vez de una simple noción $[\ldots]$ "..19.

Esta primera caracterización en torno a la vaguedad de la noción de diálogo judicial, también es compartida por Luis López Guerra, cuando sostiene que "[...] se trata de una noción que se ha empleado con significados muy distintos, que van desde la mera cita por un tribunal de resoluciones de otro hasta la presencia de una efectiva interacción entre tribunales, es decir, de un proceso de influencias recíprocas en el sentido de que un tribunal reacciona conscientemente ante la apreciación que de su conducta haya realizado otro tribunal" 20 .

Sin embargo, García Roca valora positivamente esta imprecisión conceptual del diálogo judicial, al reconducirla en clave de ductilidad y utilidad práctica en el contexto plural y multicultural europeo:

[...] paradójicamente, esta ductilidad me parece la principal virtud de la idea de cara a ser aceptada por las muy diversas culturas jurídicas de nada menos que 47 Estados sometidos a la jurisdicción del TEDH: ante un colectivo tan amplio y plural puede ser bueno no detenerse demasiado en los detalles [...]. El diálogo judicial es una noción válida precisamente por el rico pluralismo de los ordenamientos europeos y la situación de intenso multiculturalismo. Pero es verdad que no resulta claro qué quiere decirse realmente con la expresión $[\ldots]^{21}$.

\footnotetext{
17 Hurtado Pozo (1979).

18 García Roca (2012), p. 190.

19 García Roca (2012), p. 190.

20 López Guerra (2013), p. 141.

21 García Roca (2012), p. 191.
} 
Por ello, este autor concluye que no es partidario de un concepto muy estricto o restringido de diálogo judicial sino de una construcción amplia, pragmática y flexible y -es importante resaltarlo- típicamente europea ${ }^{22}$.

Nosotros compartimos este punto de partida en la aproximación conceptual a la noción de diálogo judicial: una definición amplia, pragmática y adecuada a cada realidad, dirigida a caracterizar un "proceso de influencias y relaciones recíprocas” como bien lo sintetiza López Guerra ${ }^{23}$. En otras palabras, una forma de relación dialógica entre los órganos del sistema interamericano y los tribunales nacionales, en búsqueda de una influencia y enriquecimiento recíprocos.

Es a través de este prisma inicial que debemos matizar o reinterpretar-en clave interamericana- los rasgos del diálogo judicial. Así, debe incorporarse el elemento de que en nuestro escenario de pluralismo constitucional interamericano, hay una instancia jurisdiccional final de solución de controversias que es la Corte interamericana. Sin perjuicio de la independencia de las altas Cortes nacionales y de la condición de intérprete interamericano que también comparte la Comisión interamericana, consideramos que la Corte se erige en la instancia final cuando los Estados o la Comisión deciden someter un caso a su competencia. Si bien es verdad que la Comisión puede optar por no enviar un caso a la Corte, también lo es que los casos más relevantes y en los que se busca consolidar un estándar interamericano, suelen terminar en la Corte.

Hay además una indiscutible obligación de los Estados nacionales de dar cumplimiento a las sentencias y opiniones de la Corte. Así es, el artículo 68.1 de la Convención Americana para los Derechos Humanos (CADH) establece que "[1]os Estados partes de la Convención se comprometen a cumplir la decisión de la Corte en todo caso en que sean partes". Por otro lado, el artículo 62.1 dispone que "[t]odo Estado parte puede, en el momento del depósito de su instrumento de ratificación o adhesión de esta Convención, o en cualquier

22 “[...] una construcción amplia, pragmática y flexible, típicamente europea, atenta a una deferencia recíproca y a instrumentos de colaboración [...]. Asistimos a un complejo proceso de influencia recíproca e intercambio de ideas sobre derechos entre altos tribunales: un nuevo case law creado mediante un diálogo judicial [...] es un instrumento dúctil, pero algo ambiguo, que se revela en la práctica muy útil para organizar un trabajo en red entre altos tribunales [...] permite comprender cómo deben dictarse y argumentarse las decisiones sobre derechos, fundándose en los principios de colaboración y complementariedad [...]. Me decanto pues, con realismo, en favor de un entendimiento amplio antes que estricto de la noción que no nos permitiría resolver los problemas ni explicar el funcionamiento real de un trabajo en red [...]”. GARCía Roca (2012), pp. 191 y 223.

23 López Guerra (2013), p. 141. 
momento posterior, declarar que reconoce como obligatoria de pleno de derecho y convención especial, la competencia de la Corte sobre todos los casos relativos a la interpretación o aplicación de esta Convención”. Por su parte, el artículo 64.2 de la Convención contempla que "[l] a Corte, a solicitud de un Estado miembro de la Organización, podrá darle opiniones acerca de la compatibilidad entre cualquiera de sus leyes internas y los mencionados instrumentos internacionales" 24 .

Por su parte, si bien la Corte no está en la obligación jurídica de tomar en cuenta la jurisprudencia de los tribunales nacionales, en la práctica lo ha venido haciendo en forma creciente por dos razones principalmente. Por un lado, con ello ha enriquecido el derecho interamericano al incorporar estándares de derechos humanos y técnicas de interpretación desarrollados por altas cortes nacionales. Consideramos que uno de esos casos es el examen o test de proporcionalidad, desarrollado como método de interpretación constitucional en América Latina, que la Corte ha venido incorporando en algunas de sus sentencias en los últimos años, aunque en ocasiones con ciertas imprecisiones conceptuales ${ }^{25}$.

Por otro lado, con ello ha buscado legitimar sus decisiones y a la Corte misma frente a los Estados nacionales y sus ciudadanos ${ }^{26}$. Hoy en día sería altamente inconveniente que la Corte o la Comisión optaran por ignorar los aportes jurisprudenciales de las altas Corte nacionales en materia de derecho, pues afectaría su legitimidad y abriría un flanco más en la precaria y en ocasiones conflictiva relación entre los órganos del sistema interamericano y algunos Estados miembros de la $\mathrm{OEA}^{27}$.

\footnotetext{
24 Además, esta obligación internacional de observar las decisiones de la Corte interamericana por parte de los tribunales nacionales, se funda también en el artículo $2^{\circ}$ de la CADH que consagra el deber de los Estados de adoptar disposiciones de derecho interno: "[s]i el ejercicio de los derechos y libertades mencionados en el artículo $1^{\circ}$ no estuviere ya garantizado por disposiciones legislativas o de otro carácter, los Estados partes se comprometen a adoptar [...] las medidas legislativas o de otro carácter que fueren necesarias para hacer efectivos tales derechos y libertades". Dentro de la categoría genérica de medidas "de otro carácter" cabe comprender las decisiones judiciales que, eventualmente, incorporen decisiones de la Corte interamericana para hacer efectivos determinados derechos o libertades.
}

25 Es el caso, por ejemplo, de la sentencia del Caso Artavia Murillo y otros ("Fecundación in Vitro") vs. Costa Rica. Corte Interamericana de Derechos Humanos, Serie C No 257, de 28 de noviembre de 2012.

26 Con este mismo propósito legitimador, la Corte y Comisión también han incorporado argumentos y precedentes del sistema universal y el sistema europeo de derechos humanos, en clave de criterios de interpretación. Nuevamente, sin estar obligadas a hacerlo sino porque enriquece y legitima su jurisprudencia.

27 Algo similar acontece en Europa, donde el TEDH tampoco está obligado jurídicamente a dialogar con los tribunales nacionales pero en la práctica lo hace en forma "espontánea", tal como lo señala García Roca: "[...] Ni las normas del Convenio Europeo de Derechos Humanos ni sus Protocolos ni si Reglamento 
De esta manera, en la práctica del sistema interamericano la influencia entre Corte/Comisión y tribunales nacionales, es recíproca y no unidireccional. Nosotros preferimos caracterizar esta relación plural y de influencia recíproca entre los ámbitos interamericano y nacional como "articulación dialógica" 28 y no como "diálogo judicial", pues tal relación se da a tres bandas: i) entre la Corte y los tribunales nacionales, ii) entre la Comisión y los tribunales nacionales y iii) entre la Corte y la Comisión; tómese además en cuenta que este último órgano del SIDH no tiene carácter judicial.

Ciertamente esta articulación dialógica no siempre supondrá una influencia recíproca y, en ese sentido, no está exenta de tensiones y conflictos. En ocasiones los Estados o tribunales nacionales abiertamente han discrepado de las decisiones de la Corte o de la Comisión, aunque escasas veces ello ha supuesto el no acatamiento de las mismas. Sobre el particular algunos autores reclaman a la Corte interamericana "[...] ser más seria respecto del tan mentado diálogo jurisprudencial, es decir, a la influencia recíproca entre los tribunales nacionales e interamericano en el desarrollo de su jurisprudencia [...]"29. Al respecto, es

interno imponen al Tribunal de Estrasburgo la obligación expresa de dialogar en la fase ascendente antes de dictar sentencia ni con los Tribunales constitucionales ni con las demás autoridades judiciales. Pero sentar esta conclusión sería formalista en exceso. La comunicación entre esos sujetos judiciales es una obligación tácita o implícita en el sistema europeo y tiende a ser espontánea [...] es inmanente a su posición en el vértice de un sistema de protección multinivel de derechos y a la eficacia ulterior de sus sentencias, que deba impulsar el diálogo con los tribunales constitucionales [...]”. GARCÍA Roca (2012), pp. 203 y 205.

28 Sobre la noción de "articulación", Marcelo Neves sostiene que "El camino más adecuado en materia de derechos humanos parece ser el 'modelo de articulación' ('engagement model'), o mejor dicho, de entrelazamiento transversal entre órdenes jurídicos, de tal modo que todas se muestren capaces de reconstruirse permanentemente mediante el aprendizaje con las experiencias de órdenes jurídicos concomitantemente interesados en la solución de los mismos problemas jurídicos constitucionales de derechos fundamentales [...]. Este entrelazamiento multiangular en torno a los derechos humanos y fundamentales no sería posible si no hubiese, en los diversos órdenes especialmente en el estatal, una disposición a ceder a las exigencias de las perspectivas de otros órdenes normativos en relación al significado y amplitud de derechos contrapuestos". Neves (2015), pp. 110-111. La tesis de este autor del "transconstitucionalismo" si bien es sugerente, no la compartimos porque seguimos creyendo que la noción de "articulación dialógica" grafica mejor la relación entre Corte y Comisión y tribunales nacionales.

29 Dulitzky (2014), p. 560. El referido autor sostiene que: "La Corte a través de sus sentencias debería crear una doctrina apropiada sobre el valor que la interpretación de los jueces latinoamericanos tiene para el desarrollo del contenido de la Convención Americana. Hasta ahora, el tribunal no ha elaborado siquiera mínimamente cuál es el valor de tal jurisprudencia latinoamericana. P. ej., la Corte no explica si la jurisprudencia latinoamericana sirve como ejemplo de buena práctica, como guía o pauta para la interpretación que desarrolla la propia Corte, como apoyo de su propia interpretación o para indicar que la Convención está siendo interpretada de acuerdo a un consenso regional reflejado en la jurisprudencia de los países [...]. Dudamos de que sea aconsejable que el consenso regional sea un factor determinante en la interpretación 
cierto que ni la Comisión ni la Corte han desarrollado en forma sistemática el valor o influencia que tiene en sus decisiones, la jurisprudencia de los tribunales nacionales.

\section{2. ¿Margen DE APRECIACIÓN NACIONAL EN EL SIDH?}

En este contexto interamericano brevemente descrito de reposicionamiento de los Estados nacionales en un contexto de pluralismo normativo entre el derecho internacional y el derecho nacional y de creciente articulación dialógica entre los órganos del sistema interamericano y los tribunales nacionales, surge la interrogante de si en dicho andamiaje institucional debería acogerse $-\mathrm{o}$ nola noción de margen de apreciación nacional surgida en el Sistema europeo de derechos humanos. Para responder a tal interrogante, toca distinguir dos supuestos. Primero, cuando en un caso concreto la Corte IDH determina si hubo -o no- violación de derechos fundamentales por parte de un Estado. Segundo, cuando la Corte ya emitió una sentencia condenatoria y toca implementar -en vía de ejecución- lo dispuesto en ella por parte del Estado respectivo.

\subsection{Margen de apreciación nacional surgido en Sistema europeo de derechos humanos}

El margen de apreciación nacional es una noción que surge en el sistema europeo de derechos humanos, en el cual se ha desarrollado. Al respecto, consideramos que la posible incorporación -o no- del margen de apreciación nacional en el SIDH, merece una aproximación crítica en torno a la necesidad y conveniencia de tal incorporación, tomando en cuenta nuestra realidad, parcialmente distinta a la europea comunitaria. Adelantamos que nuestra posición es que no es necesario ni conveniente asentar esta noción de margen de apreciación nacional en predios interamericanos, sino que basta con aplicar los principios de subsidiariedad y de proporcionalidad.

Según Javier García Roca, el término "margen de apreciación” no tiene origen en el derecho internacional ni comunitario sino que parece haber provenido de Francia y, más concretamente, del Consejo de Estado y del derecho administra-

de la Convención. En una región donde hay tantas deudas en materia de derechos humanos, dar deferencia al consenso regional implicaría bajar muchos estándares de protección [...] El consenso regional puede ser una de las pautas de interpretación pero ni la primera ni la principal [...]”. DULITZKY (2014), pp. 557-558. 
tivo francés, en el que existe un margen de discrecionalidad que se le reconoce a la Administración ${ }^{30}$.

Según este mismo autor, fue la desaparecida Comisión Europea de Derechos Humanos la que, por primera vez, utilizó esta noción de margen de apreciación nacional en el caso del Reino Unido contra Grecia en 1958, por la adopción de medidas de emergencia en la isla de Chipre ${ }^{31}$. Luego, el TEDH abraza esta noción y la incorpora en su jurisprudencia. Queda claro así que -en un inicioel margen de apreciación nacional estuvo ligado a situaciones excepcionales de emergencia, que en clave interamericana, son las que contempla el artículo 27 de la CADH.

El margen de apreciación nacional no es otra cosa, en palabras de García Roca, que "[...] 'un espacio de maniobra' que las instituciones de Estrasburgo están dispuestas a conceder a las autoridades internas en el cumplimiento de sus obligaciones derivadas del Convenio Europeo [...]. La idea básica es que los Estados partes tienen un cierto margen de discrecionalidad en la aplicación y el cumplimiento de las obligaciones impuestas por el Convenio y en la ponderación de intereses complejos [...]"32.

Como se puede apreciar, la noción de margen de apreciación nacional supone un "margen de maniobra" que el TEDH concede a los Estados nacionales en dos supuestos: i) "la ponderación de intereses complejos", esto es, la determinación de si hubo o no violación de derechos fundamentales y ii) la implementación y cumplimiento de lo dispuesto por el TEDH.

Sin embargo, esta aproximación conceptual de constituir un "margen de maniobra" concedido a los Estados nacionales, adolece de una gran vaguedad e imprecisión y esa es, precisamente, una de las principales críticas que se le hacen porque -más allá de su utilidad práctica para tomar en cuenta particularidades nacionales y culturales en el específico contexto europeo-, en ocasiones ha sido

\footnotetext{
30 "El origen del margen de apreciación nacional es bastante oscuro, no parece proceder del Derecho Internacional y el término no está en el Convenio ni en los trabajos preparatorios. El origen de esa expresión no es evidente para los juristas de habla inglesa, diferencia de en Francia, de donde parece proceder [...] Consejo de Estado francés que usa la expresión 'marge d'appréciation'; y que se aproxima a la idea de discrecionalidad administrativa, que usa la jurisprudencia administrativa [...]”. GarCía Roca (2010), pp. 107-108.

31 García Roca (2010), p. 109.

32 García Roca (2010), pp. 108 y 113.
} 
usada como pretexto por el TEDH para no entrar a evaluar una situación nacional concreta por consideraciones diversas y a veces hasta contradictorias.

Es una noción que ha sido objeto de polémica y valoraciones opuestas en Europa, desde quienes consideran que es "[...] una doctrina tan resbaladiza y elusiva como una anguila, una aproximación oportunista donde el TEDH abdica de su responsabilidad [...]"33, hasta quienes, por el contrario, sostienen que es "[...] una muestra acertada de contención (selfrestraint) y prudencia judiciales, $y$, al cabo de realismo, un ejemplo de respeto al pluralismo jurídico de base territorial y a la diversidad cultural de las naciones europeas [...]"34.

Una posición intermedia es la que asume precisamente García Roca, quien -si bien considera que la noción de margen de apreciación nacional ha sido útil en Europa-, tiene un acercamiento muy crítico a determinados usos distorsionados que se han hecho de la misma ${ }^{35}$. Pese a ello, para este autor hay dos razones para considerar válida la noción de margen: i) permite adecuar las decisiones del TEDH a la realidad plural y multicultural europea y ii) es una plasmación del principio de subsidiariedad del derecho internacional ${ }^{36}$.

\subsection{Los rasgos peculiares de América Latina}

Vista la noción del margen de apreciación nacional surgida en Europa y algunas apreciaciones críticas en torno a la misma, corresponde ahora reflexionar si la misma es trasladable -o no- al contexto interamericano. Si bien somos un continente territorialmente extenso, con treinta y cinco Estados, ocho de los cuales son pequeños Estados caribeños y un continente cultural y lingüísticamente diverso con valiosas lenguas indígenas, a la vez contamos con sólo cuatro

33 García Roca (2010), pp. 119-120.

34 García Roca (2010), pp. 120-121.

35 "[...] el margen no puede concebirse como una 'carta blanca' a los Estados [...]. El margen comporta un cierto poder 'discrecional', pero no entraña un espacio que se deje a la 'arbitrariedad' de los Estados". García Roca (2010), pp. 130-131.

36 "Un cierto margen de apreciación nacional -se llame como se quiera- en la regulación y ponderación de los derechos recogidos en el Convenio parece necesario por dos razones. Primero, porque refleja una evidente realidad, el fuerte pluralismo territorial de los pueblos europeos [...] la tremenda diversidad de los 47 Estados [...] en segundo lugar, todo ello responde también a la lógica de la que es una protección 'internacional' o 'supranacional' en cualquier caso subsidiaria de la interna que dispensen los Estados [...]”. García Roca (2010), pp. 123-124. 
idiomas oficiales en la Organización de los Estados Americanos (OEA): inglés, español, portugués y francés.

Por su parte, la religión católica es la mayoritaria, sin perjuicio de la existencia de otras creencias cristianas y, en menor medida, de otras religiones, en una atmósfera de tolerancia. A nivel de tradiciones jurídicas, el civil law es propio de los países latinoamericanos y el common law de los países anglófonos (Estados Unidos, Canadá y la mayor parte de países caribeños).

En consecuencia, a grandes rasgos podríamos afirmar que en el concierto interamericano, se distinguen tres grandes áreas geográficas y culturales: América del norte anglófona (Canadá y Estados Unidos), el Caribe y América Latina. Ciertamente cada subregión y país presenta sus propias peculiaridades, pero en términos generales podemos afirmar que al menos dentro de cada uno de los tres grandes bloques territoriales que hemos mencionado, hay cierta proximidad histórica y cultural.

En el caso del sistema interamericano, en la actualidad hay mayor proximidad jurídica (civil law), histórica y cultural, pues están sometidos al mismo casi todos los Estados latinoamericanos y sólo algunos caribeños, pero aún no Estados Unidos, Canadá y otros países caribeños anglófonos de tradición jurídica de common law. De esta manera, el concierto interamericano no muestra la contemporánea y en ocasiones conflictiva pluralidad cultural y religiosa europea.

Tal vez ha sido el ámbito de las confesiones religiosas en donde el TEDH se ha mostrado más cauteloso en evaluar algunas decisiones estatales y ha sido, por ende, más proclive a reconocer un margen de apreciación nacional. Francisco Barbosa señala que en el caso de Francia hay una histórica tradición de laicidad en la enseñanza pública y que la misma, al entrar en conflicto con algunas expresiones religiosas, como el islamismo, ha merecido pronunciamientos por parte del TEDH en el que se reconoce a favor no sólo de Francia sino también de Italia y Turquía, un margen de apreciación considerable: "En el marco de esa noción de pluralismo educativo, el TEDH ha sido muy cuidadoso de imponer un criterio para no contrariar la noción de laicidad a la francesa, o turca o italiana, entre otras" 37.

37 BARBOSA (2011), p. 57. Es importante destacar que este mismo autor concluye con una consideración crítica frente al margen de apreciación nacional sobre la laicidad de la enseñanza pública, en el sentido que considera que el TEDH no debería seguir rehusando a analizar dicha característica de la enseñanza pública, sino que debería a entrar a analizar el fondo de la tensión entre aquella y las creencias religiosas. BARBOSA (2011), p. 61. 
En consecuencia, consideramos que esa utilidad práctica que se invoca como una de las razones que justificarían el margen de apreciación nacional en la realidad europea, no debería ser trasladable mecánicamente al sistema interamericano. Si bien es cierto somos un continente diverso, tal diversidad ha venido siendo armonizada jurídicamente y en forma creciente a partir de los estándares de derechos humanos construidos por el sistema interamericano de derechos humanos, el mismo que se rige -como todo sistema internacional de protección de derechos y entre otros principios- por los de subsidiariedad y de proporcionalidad.

Esta armonización jurídica interamericana se verifica sobre todo en nuestra región denominada geográfica, histórica y culturalmente como "América Latina", en la que, gracias a la labor de los órganos del SIDH, se ha venido gestando lo que algunos autores como Armin von Bogdandy denominan un Ius constitucionale commune, un derecho constitucional común en torno al contenido y tutela de los derechos fundamentales. Al respecto, dicho autor alemán afirma:

Referirse al fenómeno en tanto que derecho común (Ius Commune) se justifica por dos componentes esenciales [...] El primer componente consiste en la nueva apertura de los ordenamientos jurídicos estatales latinoamericanos hacia un estrato común de derecho internacional público, sobre todo hacia la Convención Americana. [...] Los derechos constitucionales estatales y el derecho internacional público, se encuentran en una relación de fortalecimiento mutuo [...] Esta apertura es entonces expresión de un desarrollo común, que además les confiere a los ordenamientos jurídicos estatales una orientación común. [...] Se trata asimismo de un cambio común, ya que vincular el derecho estatal con el derecho internacional público constituye una ruptura en la manera tradicional de estudiar estas dos áreas del derecho, puesto que tradicionalmente su tratamiento académico e investigación se desarrolla por separado [...] El Ius Constitucionale Commune en América Latina representa un enfoque transformador [...] Su sustrato de derecho positivo lo constituye principalmente la Convención Americana sobre Derechos Humanos ${ }^{38}$.

En consecuencia, la utilidad práctica que en Europa supuestamente pueda tener la noción de margen de apreciación nacional, no se vislumbra en América Latina que, gracias al corpus iuris interamericano, ha ido gestando un piso mínimo común de derechos fundamentales que no sólo no impide sino que, por el contrario, potencia la diversidad cultural como en el caso de los pueblos indígenas

38 Bogdandy (2005), pp. 10, 36. 
y comunidades afrodescendientes, que han logrado avances significativos en el reconocimiento de sus derechos, gracias precisamente al SIDH. En ese sentido, internacionalistas como Matthias Herdegen sostienen que "[...] el dinámico desarrollo de los estándares en materia de derechos humanos ha encogido la esfera interna de los Estados en lo que concierne a la libre configuración de los asuntos relacionados con su ámbito interno [... ${ }^{39 ”}$.

\subsection{Principio de subsidiariedad en el SIDH}

Como se sabe, el sistema interamericano -como todo sistema internacional de derechos humanos- ostenta un carácter subsidiario respecto a los sistemas de justicia nacionales: sólo entra en acción si es que los tribunales nacionales no han protegido debidamente los derechos fundamentales vulnerados y previamente la presunta víctima ha agotado los recursos internos, salvo en situaciones excepcionales contempladas expresamente en el artículo 46.2 de la $\mathrm{CADH}$.

Esa naturaleza subsidiaria está reconocida no sólo en la $\mathrm{CADH}$ sino también en las Constituciones políticas nacionales. En el caso de la CADH, el artículo 46.1.a) establece: "Para que una petición o comunicación presentada conforme a los artículos 44 o 45 sea admitida por la Comisión, se requerirá [...] que se hayan interpuesto y agotado los recursos de jurisdicción interna, conforme a los principios del Derecho Internacional generalmente reconocidos". Es decir, para echar a andar el sistema de peticiones individuales ante la $\mathrm{CIDH}$, la $\mathrm{CADH}$ exige -como uno de los requisitos de admisibilidad- que se haya agotado la vía interna y no se haya obtenido protección satisfactoria a los derechos fundamentales alegados.

En el caso de Constituciones nacionales como la del Perú, el artículo 205 establece que "Agotada la jurisdicción interna, quien se considere lesionado en los derechos que la Constitución reconoce, puede recurrir a los tribunales u organismos internacionales constituidos según tratados o convenios de los que el Perú es parte". Nuevamente, es claro que para activar el sistema interamericano se requiere haber agotado la vía interna.

En eso consiste el principio de subsidiariedad y ese es uno de los pilares de todo el sistema de peticiones individuales regulado por la $\mathrm{CADH}$, el Estatuto y Reglamento de la Comisión interamericana. Además, es uno de los requisitos

39 Herdegen (2015), p. 44. 
de admisibilidad de dichas peticiones, junto con otros como el de la cuarta instancia, el plazo de seis meses, entre otros.

Por su parte, la noción de margen de apreciación nacional es otra de las plasmaciones del principio de subsidiariedad, surgida en el ámbito europeo. Como sostiene García Roca: "La llamada doctrina del margen -pese a que concluiremos que no es una verdadera doctrina- [...] es inmanente a la lógica del principio de subsidiariedad, inherente a una protección internacional [...]"40.

Sin embargo, tal como hemos visto, en el concierto interamericano el principio de subsidiariedad tiene concreciones diferentes, bastante desarrolladas por los informes de admisibilidad o inadmisibilidad de la CIDH y por la jurisprudencia de la Corte: el criterio de la cuarta instancia, el agotamiento de la vía interna, qué debe entenderse por vía interna, las excepciones válidas al agotamiento de la vía interna, entre otros criterios.

De esta manera, mientras que en el ámbito europeo en ocasiones el TEDH le concede a los Estados nacionales un margen o apreciación nacional o "margen de maniobra" sin control jurisdiccional internacional, en cambio en el ámbito interamericano el principio de subsidiariedad se concreta en la admisión -o node peticiones que previamente hayan agotado -o no- la jurisdicción interna, en el caso de la CIDH.

En el caso de la Corte, la subsidiariedad se plasmará en la mayor o menor flexibilidad que tengan los Estados al momento de cumplir las medidas dispuestas por una sentencia de la Corte. Autores como César Landa consideran que en este nivel hay lugar para reconocer un margen de apreciación nacional ${ }^{41}$. Sin embargo, en nuestra opinión en este nivel tampoco es necesario ni conveniente incorporar la noción de margen de apreciación nacional, pues la mayor o menor flexibilidad que los Estados puedan tener para implementar lo dispuesto por la Comisión o la Corte en un caso concreto, no es consecuencia de la existencia de un supuesto "margen de apreciación" o "margen de maniobra", sino de la naturaleza de las medidas de justicia, reparación y no repetición que estos órganos

\footnotetext{
40 García Roca (2010), pp. 93-94.

41 “[...] el margen de apreciación entiendo que innominadamente lo ha hecho la Corte más que en los fallos de fondo, en las reparaciones que deja que se implemente de acuerdo a la legislación nacional. Pero, en algunos casos de fondo ha señalado que el tipo penal p.e. de desaparición forzada no está completo y que el legislador debe rellenarlo (Caso Gómez Palomino contra Perú); también cuando pide que se diferencie el tipo penal de calumnia y difamación (Caso Kimel contra Argentina)". Landa (2015b).
} 
interamericanos dispongan. Naturaleza que puede suponer una menor o mayor flexibilidad con la que los Estados cuentan para implementar tales medidas.

Por ejemplo, si la Corte dispone que un Estado tipifique un delito contra los derechos humanos o complete o corrija una tipificación penal ya existente -para hacerla compatible con la $\mathrm{CADH}-$, entonces las autoridades nacionales pueden hacerlo modificando el Código Penal, aprobando una ley especial, vía el propio Congreso o por delegación legislativa. Asimismo, la Corte puede disponer la implementación de un Plan nacional de búsqueda de personas desaparecidas en el contexto de lo que fue un conflicto armado interno, en cuyo caso el Estado decidirá aprobarlo por ley, por norma reglamentaria, insertado en un sector determinado o como órgano autónomo, con determinado presupuesto, entre otros aspectos.

En cambio, cuando la Comisión o la Corte disponen la realización de un nuevo proceso judicial para individualizar y sancionar a los victimarios, modificar las condiciones de privación de libertad para evitar nuevos episodios de tortura o trato cruel o denigrante o reparar económica y simbólicamente a las víctimas, sólo cabe que el Estado cumpla con ello. En otras palabras, no será el mayor o menor margen de apreciación, sino la mayor flexibilidad o rigidez que tendrá el Estado para el cumplimiento de las decisiones interamericanas, estará en función del tipo de obligaciones concretas que la Comisión o la Corte dispongan en cada caso.

\subsection{Examen de proporcionalidad en el SIDH}

Por su parte, el principio o examen de proporcionalidad o de ponderación, es una técnica de interpretación constitucional que paulatinamente viene siendo acogida por la Corte, aunque aún sin el suficiente rigor jurídico. Como se sabe, Robert Alexy plantea distinguir entre reglas y principios:

[Mientras que] las reglas son normas que exigen algo en forma definitiva. Ellas son, por lo tanto, mandatos definitivos. Su forma de aplicación es la subsunción [...]. Por el contrario, los principios son mandatos de optimización. Como tales, ellos exigen que algo sea realizado en la mayor medida posible, de acuerdo a las posibilidades fácticas y jurídicas existentes. A diferencia de las reglas, las posibilidades jurídicas están determinadas esencialmente por los principios opuestos... La determinación del grado apropiado de satisfacción de un principio respecto a lo que ordena otro principio, se determina por medio de la ponderación $[\ldots]^{42}$.

42 Alexy (2011), pp. 12-13. 
De esta manera, Alexy planteó que este principio o examen de proporcionalidad o ponderación debía ser realizado de la manera siguiente:

El principio de proporcionalidad, mismo que en las últimas décadas ha recibido gran reconocimiento dentro de la teoría y práctica de la jurisprudencia constitucional, está conformado por tres sub-principios: el principio de idoneidad, el de necesidad y el de proporcionalidad en sentido estricto. Estos tres principios expresan en su conjunto la idea de optimización [...] Los principios de idoneidad y de necesidad se refieren a la optimización respecto de las posibilidades fácticas. El principio de proporcionalidad en sentido estricto se refiere a la optimización respecto de las posibilidades jurídicas ${ }^{43}$.

Ahora bien, volviendo a aterrizar en el ámbito del cumplimiento de las sentencias emitidas por la Corte, si el Estado adujera la tensión con otros derechos fundamentales en el proceso de su implementación, la Corte podría realizar -eventualmente- un examen de proporcionalidad en las audiencias y resoluciones de supervisión de cumplimiento de sus sentencias. Al respecto, es interesante la distinción que Laura Clérico hace entre normas-regla y normas-principio, en relación con la aplicación -o no- por parte de la Corte IDH del examen de proporcionalidad $^{44}$, pero que consideramos extensible al tipo de relación que en un caso concreto puede establecerse entre los órganos interamericanos y tribunales nacionales.

Para Clérico, en materia de derechos humanos, la proporcionalidad se aplicará a normas-principio (p. e. libertad de expresión vs. derecho al honor) y la subsunción se aplicará a normas-regla (p. e. prohibición de la tortura). Para el propósito del presente artículo, desprendemos que puede haber mayor flexibilidad para el Estado (flexibilidad entendida como ponderación) en la implementación de una decisión interamericana cuando se trate de normas-principio y, por el contrario, puede que lo que corresponda sea un mero acatamiento de una sentencia interamericana cuando se trate de normas-regla.

Por su parte, son escasos los mandatos de la Corte (sean normas-principio o normas-regla) que son de aplicación inmediata pues -como regla general- las medidas dispuestas por sus sentencias condenatorias requerirán de medidas nacionales para su implementación. Ciertamente hay excepciones a dicha regla general de intermediación nacional y una de ellas es la sostenida jurisprudencia

43 Alexy (2011), p. 13.
44 Clérico (2012), pp. 202-203. 
interamericana -que comenzó con el Caso Barrios Altos vs. Perú45 en torno a la carencia de efecto jurídico alguno de las leyes de amnistía respecto de graves violaciones a los derechos humanos. En estos casos, las sentencias de la Corte han sido aplicadas de forma directa en los procesos judiciales respectivos, sin intermediación nacional alguna como leyes derogatorias u otras medidas similares ${ }^{46}$.

En el otro supuesto que anunciamos al inicio del presente capítulo 2, esto es, la aplicación del examen de proporcionalidad cuando la Comisión o la Corte determinan si hubo -o no- violación de derechos fundamentales en un caso concreto, estos órganos también pueden analizar -complementariamente- la naturaleza democrática -o no- de la medida nacional bajo análisis, sin necesidad de acudir tampoco a la noción de margen de apreciación nacional.

Así es, los órganos del SIDH pueden incorporar en su argumentación el carácter democrático -o no- del fin perseguido con la restricción o limitación de un derecho fundamental, en virtud de lo dispuesto en los artículos 27 y 29 de la CADH y en el artículo $5^{\circ}$ del Protocolo adicional de San Salvador. De esta manera, la Comisión o la Corte pueden evaluar la convencionalidad o no de la medida o restricción nacional adoptada, tomando en cuenta su carácter democrático -o no-, siendo innecesario -también en este caso- recurrir a la noción de margen de apreciación nacional pues se recurre más bien a una cláusula democrática ya consagrada en los instrumentos internacionales ya citados.

Nuestra experiencia con el sistema interamericano durante los últimos quince años -en especial con la Comisión $-{ }^{47}$ nos ha permitido escuchar o asistir a diversas presentaciones y conferencias por parte de representantes de los Estados, de la sociedad civil y funcionarios de la OEA y la CIDH. Un argumento escuchado a representantes de algunos Estados Miembros ha sido que a los gobiernos democráticos la CIDH no debería seguir tratándolos como dictaduras. Si bien ello

45 Corte Interamericana de Derechos Humanos, Serie C No 75, de 14 de marzo de 2001.

46 En el derecho internacional público, este efecto de aplicación inmediata en sede nacional de una disposición internacional se denomina self-executing: "Si las disposiciones de un tratado internacional por la certeza de su contenido, pueden ser aplicadas por las cortes y autoridades nacionales, se habla de una aplicabilidad directa. Este tipo de tratados se conoce en lenguaje angloamericano como self-executing [...]". Herdegen (2005), p. 170.

47 El autor participa como representante de organizaciones de sociedad civil en los períodos de sesiones de la CIDH desde el año 2001 hasta la fecha. En muchas ocasiones ha participado como peticionario o copeticionario de audiencias públicas ante dicho órgano del sistema interamericano, así como en diversas actividades convocadas por la CIDH: consultas a sociedad civil, grupos de expertos, presentación de informes temáticos, entre otros. 
es atendible, a la vez las democracias en América Latina deberían comportarse como tal y no como dictaduras del pasado al enfrentar, por ejemplo, protestas sociales en forma violenta o desproporcionada o encargar a las Fuerzas Armadas el control del orden interno.

Finalmente, el autor Pablo Contreras identifica en la jurisprudencia interamericana dos casos excepcionales en los que la Corte habría aplicado el margen de apreciación nacional, pero que nosotros consideramos que fueron expresión de los principios de subsidiariedad y proporcionalidad en el sistema interamericano ${ }^{48}$.

El primer caso fue la Opinión Consultiva OC-4/84 del 19 de enero de 1984, en virtud de la cual la Corte dio respuesta a una consulta del Estado de Costa Rica en relación a una reforma constitucional en materia de otorgamiento de la ciudadanía costarricense y en la cual se distinguía entre quienes habían nacido en dicho país y los que no ${ }^{49}$.

$\mathrm{Al}$ respecto, Contreras sostiene:

La consulta del Estado estaba relacionada con las presuntas incompatibilidades entre el derecho a la nacionalidad (art. $20 \mathrm{CADH}$ ) y la igualdad ante la ley (art. 24 $\mathrm{CADH}$ ) en la reforma propuesta [...]. En su razonamiento, la opinión reconoce que " $[\mathrm{s}] \mathrm{e}$ trata de valores que adquieren dimensiones concretas a la luz de la realidad en que están llamados a materializarse y que dejan un cierto margen de apreciación para la expresión que deben asumir en cada caso". Explícitamente, la Corte sostiene que "no puede ponerse en duda la potestad soberana de Costa Rica para resolver sobre los criterios que han de orientar el discernimiento o no de la nacionalidad de los extranjeros que aspiran a obtenerla, ni para establecer ciertas diferencias razonables con base a circunstancias de hecho que, por razones objetivas, aproximen a unos aspirantes más que a otros al sistema de valores e intereses de la sociedad costarricense". La Corte, bajo tal estándar de deferencia, estimó que las diferencias anotadas eran compatibles con la igualdad ante la ley $[\ldots]^{50}$.

Si bien es verdad la Corte utilizó la expresión "cierto margen de apreciación” a favor del Estado de Costa Rica, no creemos que ello alcance para considerar que la jurisprudencia interamericana incorporó la noción de margen de apreciación nacional, por las razones siguientes:

48 Contreras (2014), pp. 235-274.

49 Corte Interamericana de Derechos Humanos, Opinión Consultiva OC-4/84, de 19 de enero de 1984.

50 Contreras (2014), p. 241. 
- Es una decisión antigua emitida hace 34 años, momento en el que la Corte estaba comenzando a definir sus líneas jurisprudenciales.

- En este caso concreto, la Corte respetó la voluntad constituyente costarricense de diferenciar entre nacidos y no nacidos en dicho país exclusivamente para efectos del otorgamiento de la nacionalidad y no para el reconocimiento de otros derechos fundamentales.

- Por otro lado, la Corte consideró que la igualdad no había sido vulnerada porque la misma no impide hacer diferenciaciones en tanto éstas se basen en criterios objetivos no discriminatorios. Esto es, hizo un examen de proporcionalidad.

El segundo caso en el que supuestamente la Corte IDH habría aplicado la noción de margen de apreciación nacional, es la sentencia del 6 de agosto del 2008 en el Caso Castañeda Gutman vs. Estados Unidos Mexicanos, que Contreras sintetiza de la siguiente manera:

El Estado mexicano había negado el registro de la candidatura independiente de Castañeda-Gutman para la presidencia de la Nación. Las reglas electorales en México exigen que los candidatos sean postulados por los partidos políticos, excluyendo a los independientes o las candidaturas "ciudadanas". La Corte debía resolver si la restricción que pesaba sobre candidaturas independientes violaba el derecho a participar en elecciones democráticas, bajo el artículo 23 de la $\mathrm{CADH}$. El razonamiento comienza reconociendo que "en términos generales, el derecho internacional no impone un sistema electoral determinado ni una modalidad determinada de ejercer los derechos a votar y a ser elegido". Abocándose al análisis de la restricción, la Corte acepta que "la previsión y aplicación de requisitos para ejercitar los derechos políticos no constituyen per se, una restricción indebida a los derechos políticos" 51 .

Creemos que en este caso la Corte entra a analizar el fondo del asunto, si hubo o no vulneración del derecho político a participar en elecciones, y en ese análisis considera que en materia electoral como en otros ámbitos -piénsese, por ejemplo, en los diversos sistemas de selección y nombramiento de jueces y fiscales, que no necesariamente vulneran per se la independencia judicial-, hay diferentes sistemas electorales democráticos y que ninguno de ellos vulnera -per se- el artículo 23 de la CADH.

Sin embargo, fue una decisión polémica porque bien pudo optar por otro derrotero de interpretación y llegar a determinar que la prohibición de candidatos a la presidencia de la República por fuera de los partidos políticos, sí podría violar

51 Contreras (2014), p. 248. 
el derecho fundamental a la participación política. Tal vez por esto último -contradictoriamente- termina exhortando al Estado mexicano a reflexionar sobre la conveniencia de aprobar reformas legales dirigidas a ampliar la participación electoral de candidatos independientes.

En ese sentido, fue una decisión conservadora y criticable en la interpretación de las limitaciones válidas al artículo 23 de la $\mathrm{CADH}$, pero que no puede predicarse de la misma que echó mano de la noción del margen de apreciación nacional. En todo caso, puede criticársele que hizo un equivocado examen de proporcionalidad, al no ponderar correctamente el derecho fundamental a la participación política, con la naturaleza democrática de diseños institucionales electorales que restringen -desproporcionadamente, en nuestra opinión-el ejercicio de este derecho por parte de candidatos independientes por fuera de los partidos políticos.

Cabe precisar que la aplicación que lleva a cabo la jurisprudencia de la Corte en torno al examen de proporcionalidad, no necesariamente coincide con la aplicación que del mismo hace el derecho constitucional en la actualidad. Si bien para la interpretación constitucional el examen o test de proporcionalidad supone seguir en forma ordenada los pasos de idoneidad, necesidad y proporcionalidad strictu sensu, en la jurisprudencia interamericana en ocasiones sólo suponen un balance y valoración sobre si las restricciones a un derecho se justifican y es proporcional -o no- a favor del goce de otro derecho.

$\mathrm{Al}$ respecto, el 30 de mayo del 2018 la Corte interamericana emitió una resolución de supervisión de cumplimiento de sentencia en los casos Barrios Altos vs. Perú y La Cantuta vs. Perú, a propósito del indulto humanitario concedido al ex Presidente Alberto Fujimori el 24 de diciembre del 2017 por el entonces Presidente de la República del Perú, Pedro Pablo Kuczynski. En dicha resolución, la Corte sostiene que en este caso le corresponde a la jurisdicción nacional realizar un examen de proporcionalidad para determinar la convencionalidad -o no- del indulto humanitario concedido a Fujimori. Dicho examen de proporcionalidad debe realizarse-según la Corte- entre los derechos fundamentales de las víctimas y sus familiares, como el derecho de acceso a la justicia y, por otro lado, derechos fundamentales de Fujimori como la vida y la integridad:

La Corte [...] valorará la posibilidad de que en el Perú se realice el control jurisdiccional del indulto concedido "por razones humanitarias", de manera que un órgano jurisdiccional pueda verificar la proporcionalidad entre una medida otorgada por el Ejecutivo para resguardar el derecho a la vida e integridad de una persona condenada 
penalmente por graves violaciones a los derechos humanos y el derecho de acceso a la justicia de las víctimas y sus familiares $[\ldots]^{52}$.

De esta manera, la Corte remite a la jurisdicción nacional la realización del examen de proporcionalidad sobre una medida adoptada por el Estado peruano -como el indulto humanitario a Fujimori-, en el marco del cumplimiento de sentencias ya emitidas y que, entre otras medidas, establecieron la obligación de investigar, juzgar y, de ser el caso, sancionar a los responsables de estos terribles hechos. Pero en ningún momento señala que el Estado nacional y sus tribunales tienen margen de apreciación nacional alguno, sino que, por el contrario, deben sujetarse a los estándares de derechos humanos establecidos en la referida resolución de supervisión del 30 de mayo del 2018.

Además, recuerda a los jueces y tribunales nacionales su obligación de aplicar el control de convencionalidad, en este caso concreto, sobre el indulto humanitario concedido a Fujimori:

La Corte recuerda que todas las autoridades de un Estado Parte en la Convención Americana, entre ellos los jueces y órganos vinculados a la administración de justicia, tienen la obligación de ejercer un "control de convencionalidad", evidentemente, en el marco de sus respectivas competencias y de las regulaciones procesales correspondientes, de forma tal que la interpretación y aplicación del derecho nacional sea consistente con las obligaciones internacionales del Estado en materia de derechos humanos [...] este Tribunal ha indicado que, en lo que respecta a la implementación de una determinada sentencia de la Corte Interamericana, "el órgano judicial tiene la función de hacer prevalecer la Convención Americana y los fallos de esta Corte sobre la normatividad interna, interpretaciones y prácticas que obstruyan el cumplimiento de lo dispuesto en un determinado caso" 53 .

\section{CONCLUSIÓN}

En resumen, nuestra posición es que no es necesaria ni conveniente la incorporación en el SIDH de la polémica noción europea del margen de apreciación nacional. En la revisión de los actos y normas estatales por parte de los órganos

\footnotetext{
52 Corte Interamericana de Derechos Humanos, Resolución de supervisión de cumplimiento de sentencia, de 30 de mayo de 2018, párrafo 58.

53 Corte Interamericana de Derechos Humanos, Resolución de supervisión de cumplimiento de sentencia, de 30 de mayo de 2018, párrafo 65.
} 
interamericanos y en la posterior implementación de sus decisiones en sede nacional, se puede seguir recurriendo -como lo han venido haciendo la Comisión y la Corte todos estos años-, a otras plasmaciones de los principios de subsidiariedad y de proporcionalidad, en el marco de la creciente articulación dialógica entre el SIDH y los tribunales nacionales.

En la determinación si un derecho ha sido o no violado por parte de un Estado, la Corte recurre crecientemente al examen de proporcionalidad cuando hay derechos fundamentales y normas-principio en tensión; además, suele recurrir también a la cláusula democrática consagrada tanto por la CADH como por el Protocolo Adicional de San Salvador. Por su parte, en el ámbito de la ejecución de las decisiones del SIDH, la mayor o menor flexibilidad con la que los Estados cuentan al implementarlas, proviene del carácter de principios o reglas de las obligaciones impuestas al Estado nacional y no de un supuesto margen de apreciación nacional.

Si bien reconocemos que la noción de margen de apreciación nacional es una concreción de los principios de subsidiariedad y proporcionalidad en el ámbito del Sistema europeo de derechos humanos, reiteramos que consideramos innecesario e inconveniente que se incorpore la misma al Sistema interamericano de derechos humanos. Además, el autor también considera la inconveniencia de tal importación porque podría abrir un peligroso "margen de impunidad nacional" a favor de regímenes autoritarios que aún no están desterrados del todo en nuestro continente.

\section{Bibliografía CITADA}

Alexy, Robert (2011). "Los derechos fundamentales y el principio de proporcionalidad”, en Revista Española de Derecho Constitucional (No 91), pp. 11-29.

Barbosa Delgado, Francisco Roberto (2011). "El principio de laicidad en la educación en Francia y en el Tribunal Europeo de Derechos Humanos: entre el universalismo francés y el reconocimiento al margen nacional de apreciación del TEDH", en Revista OASIS (No 16), pp. 45-63, [fecha de consulta: 1 de diciembre de 2017]. [Disponible en: http://revistas.uexternado.edu.co/ index.php/oasis/article/view/3549/3585].

BAZÁN, Víctor (2012). "El control de convencionalidad: incógnitas, desafíos y perspectivas", en Bazán, Víctor y Nash, Claudio (edit.), Justicia constitucional y derechos fundamentales: el control de convencionalidad 2011, (Bogotá, 
Centro de Derechos Humanos de la Facultad de Derecho de la Universidad de Chile/Fundación Konrad Adenauer), pp. 17-55.

Bogdandy, Armin von; Ferrer Mac-Gregor, Eduardo y Morales Antoniazzi, Mariela (coord.) (2010). La justicia constitucional y su internacionalización: ¿hacia un Ius Constitucionale Commune en América Latina? (México D.F., Universidad Nacional Autónoma de México, Max-Planck Institut e Instituto Iberoamericano de Derecho Constitucional), Tomo II.

BogDAndy, Armin von (2012). "Del paradigma de la soberanía al paradigma del pluralismo normativo: una nueva perspectiva (mirada) de la relación entre el derecho internacional y los ordenamientos jurídicos nacionales”, en Griselda Capaldo, Jan Sieckmann y Laura Clérico (edit.), Internacionalización del derecho constitucional, constitucionalización del derecho internacional, (Buenos Aires, Eudeba/Fundación Alexander von Humboldt), pp. 21-40.

Bogdandy, Armin von (2013). "Ius constitucionale commune latinoamericanum. Una aclaración conceptual desde una perspectiva europea”, en González Pérez, Luis Raúl y Valadés, Diego (coord.), El constitucionalismo contemporáneo. Homenaje a Jorge Carpizo (México, UNAM), pp. 39-66.

Borowski, Martin (2000). "La restricción de los derechos fundamentales", en Revista Española de Derecho Constitucional (Año 20, No 59), pp. 29-56.

Clérico, Laura (2012). "Hacia la reconstrucción de un modelo integrado de proporcionalidad a la luz de la jurisprudencia de la Corte Interamericana de Derechos Humanos", en Griselda Capaldo, Jan Sieckmann y Laura Clérico (edit.), Internacionalización del derecho constitucional, constitucionalización del derecho internacional (Buenos Aires, Eudeba/Fundación Alexander von Humboldt), pp. 199-220.

Contreras, Pablo (2014). "Control de convencionalidad, deferencia internacional y discreción nacional en la jurisprudencia de la Corte Interamericana de Derechos Humanos", en Ius et Praxis, (Volumen 20, No 2), pp. 235-274, [fecha de consulta: 1 de diciembre de 2017]. [Disponible en: http://www. scielo.cl/pdf/iusetp/v20n2/ art07.pdf].

DulitZKY, Ariel E. (2014). "El impacto del control de convencionalidad. ¿Un cambio de paradigma en el Sistema Interamericano de Derechos Humanos?”, en Rivera (H.), Julio César, Elías, José Sebastián, Grosman, Lucas Sebastián y Legarre, Santiago (dir.), Tratado de los derechos constitucionales, (Buenos Aires, Abeledo Perrot), pp. 533-569. 
GARCíA RoCA, Javier (2010). El margen de apreciación nacional en la interpretación del Convenio Europeo de Derechos Humanos: soberanía e integración (Cizur Menor, Cuadernos Civitas/Instituto de Derecho Parlamentario).

Herdegen, Matthias (2005). Derecho Internacional Público (Traducc. Marcela Anzola (México, D.F., Universidad Nacional Autónoma de México y Fundación Konrad Adenauer).

Hurtado Pozo, José (1979). La ley importada: recepción del derecho penal en el Perú (Lima, Cedys).

LANDA ARroyo, César (2012). "Jurisdicción constitucional y jurisdicción internacional: cooperación y tensiones”, en Griselda Capaldo, Jan Sieckmann y Laura Clérico (edit.), Internacionalización del derecho constitucional, constitucionalización del derecho internacional, (Buenos Aires, Eudeba/Fundación Alexander von Humboldt), pp. 437-450.

LANDA ARroyo, César (2015a). “¿Diálogo entre la justicia constitucional y la jurisdicción internacional? Entre la incorporación y la manipulación de los estándares de derecho internacional de los derechos humanos en el ordenamiento jurídico peruano", en López Guerra, Luis y Saiz Arnaiz, Alejandro (dir.), Los sistemas interamericano y europeo de protección de los derechos humanos: una introducción desde la perspectiva del diálogo entre tribunales, (Lima, Palestra Editores), pp. 187-228.

LANDa Arroyo, César (2015b). "Re: consulta sobre un artículo tuyo" (correo electrónico del 21 de abril de 2015 a David Lovatón).

Landa Arroyo, César (2016). Convencionalización del Derecho peruano (Lima, Palestra Editores).

López Guerra, Luis (2013). "El diálogo entre el Tribunal Europeo de Derechos Humanos y los tribunales españoles. Coincidencias y divergencias", en Teoría y Realidad Constitucional, (No 32), pp. 139-158. [fecha de consulta: 1 de diciembre de 2017]. [Disponible en: http://revistas.uned.es/index.php/TRC/ article/view/11783/11230].

López Guerra, Luis y Saiz Arnaiz, Alejandro (dir.) (2015). Los sistemas interamericano y europeo de protección de los derechos humanos: una introducción desde la perspectiva del diálogo entre tribunales (Lima, Palestra Editores).

Lovatón, David (2017a). La gestación del Estado constitucional interamericano (Lima: Oficina Académica de Publicaciones, Comunicación e Imagen de la Facultad de Derecho de la Pontificia Universidad Católica del Perú). 
LOVATÓN, David (2017b). "El diálogo judicial interamericano y constitucional desde la experiencia peruana”, en Landa, César (coord.). El reto de pensar sobre los derechos fundamentales en América Latina. Actas de las Segundas Jornadas Latinoamericanas sobre Derechos Fundamentales, (Lima: Oficina Académica de Publicaciones, Comunicación e Imagen de la Facultad de Derecho de la Pontificia Universidad Católica del Perú), pp. 321-335.

Morales Antoniazzi, Mariela (2014). "El Estado abierto como objetivo del Ius Constitutionale Commune: aproximación desde el impacto de la Corte Interamericana de Derechos Humanos", en Bogdandy, Armin von, Fix-Fierro, Héctor y Morales Antoniazzi, Mariela (coord.), Ius Constitutionale Commune en América Latina: rasgos, potencialidades y desafíos (México, Universidad Nacional Autónoma de México), pp. 265-299.

Neves, Marcelo (2015). "Del diálogo entre las Cortes Supremas y la Corte Interamericana de Derechos Humanos al transconstitucionalismo en América Latina”, en López Guerra, Luis y Saiz Arnaiz, Alejandro (dir.), Los sistemas interamericano y europeo de protección de los derechos humanos: una introducción desde la perspectiva del diálogo entre tribunales, (Lima, Palestra Editores), pp. 85-118.

Saiz Arnaiz, Alejandro (2015). "Tribunal Constitucional y Tribunal Europeo de Derechos Humanos: las razones para el diálogo”, en López Guerra, Luis y Saiz Arnaiz, Alejandro (dir.), Los sistemas interamericano y europeo de protección de los derechos humanos: una introducción desde la perspectiva del diálogo entre tribunales, (Lima, Palestra Editores), pp. 153-186.

VergotTINI, Giuseppe de (2011). Más allá del diálogo entre tribunales: comparación y relación entre jurisdicciones (Madrid, Civitas/Thomson Reuters).

Vítolo, Alfredo M. (2013). “Una novedosa categoría jurídica: el 'querer ser'. Acerca del pretendido carácter normativo erga omnes de la jurisprudencia de la Corte Interamericana de Derechos Humanos. Las dos caras del 'control de convencionalidad"', en Pensamiento Constitucional, (No 18), pp. 357-380.

\section{NORMAS CITADAS}

Constitución Política del Perú (1993).

Convención Americana sobre Derechos Humanos "Pacto de San José, Costa Rica" (1969). 


\section{JURISPRUDENCIA CITADA}

Artavia Murillo y otros ("Fecundación in Vitro") vs. Costa Rica (2012). Corte Interamericana de Derechos Humanos, 28 de noviembre de 2012 (Excepciones preliminares, fondo, reparaciones y costas). Serie C No 257.

Barrios Altos vs. Perú (2001). Corte Interamericana de Derecho Humanos, 14 de marzo de 2001 (Sentencia de fondo). Serie C No 75.

Barrios Altos y La Cantuta vs. Perú (2018). Corte Interamericana de Derechos Humanos, 30 de mayo del 2018 (Resolución de supervisión de cumplimiento de sentencia).

Castañeda Gutman vs. Estados Unidos Mexicanos (2008). Corte Interamericana de Derechos Humanos, 6 de agosto de 2008 (Excepciones preliminares, fondo, reparaciones y costas). Serie C No 184.

Propuesta de Modificación a la Constitución Política de Costa Rica relacionada con la Naturalización (1984). Corte Interamericana de Derechos Humanos, 19 de enero de 1984 (Opinión Consultiva OC-4/84). Serie A No 4. 
